\title{
Surgical management of penetrating spinal cord injury primarily due to shrapnel and its effect on neurological outcome: a literature review and meta-analysis
}

\author{
Michael H. Lawless, DO, LT, MC, USNR, ${ }^{1,2}$ Evan J. Lytle, DO, ${ }^{3}$ Andrea F. McGlynn, MS, ${ }^{2}$ and \\ John A. Engler, MD, LCDR, MC, USN ${ }^{4}$ \\ Departments of ${ }^{1}$ Surgery and ${ }^{3}$ Neurosurgery, Providence-Providence Park Hospital, Michigan State University College of Human \\ Medicine, Southfield, Michigan; and ${ }^{2}$ Clinical Investigation Department and ${ }^{4}$ Department of Neurosurgery, Naval Medical Center, \\ Portsmouth, Virginia
}

OBJECTIVE This study was performed to determine whether decompression of penetrating spinal cord injury (SCl) due to explosive shrapnel leads to greater neurological recovery than conservative management.

METHODS In accordance with the Preferred Reporting Items for Systematic Reviews and Meta-Analyses (PRISMA) guidelines, a comprehensive literature search using PubMed/MEDLINE, Web of Science, Google Scholar, and the Defense Technical Information Center public site was conducted on May 2, 2016. Studies that described penetrating $\mathrm{SCl}$ with shrapnel as an etiology, included surgical and/or conservative management, and demonstrated admission and follow-up neurological status were eligible for inclusion in this study. Odds ratios were calculated for the overall effect of surgical treatment on neurological recovery. Funnel plots were used to evaluate publication bias.

RESULTS Five case series (Level IV evidence) met the study criteria, and 2 of them had estimable odds ratios for use in the Forest plot analysis. Among the patients from all 5 studies, $65 \%$ were injured by shrapnel, $25 \%$ by high-velocity bullet, $8 \%$ by low-velocity bullet, and $2 \%$ by an unknown cause. A total of 288 patients were included in the overall odds ratio calculations. Patients were stratified by complete and incomplete $\mathrm{SCl}$. The meta-analysis showed no significant difference in outcomes between surgical and conservative management in the complete SCI cohort or the incomplete SCI cohort. Overall rates of improvement for complete $\mathrm{SCI}$ were $25 \%$ with surgery and $27 \%$ with conservative treatment (OR $1.07,95 \% \mathrm{Cl} 0.44-2.61, \mathrm{p}=0.88)$; for incomplete $\mathrm{SCl}, 70 \%$ with surgery and $81 \%$ with conservative treatment (OR 1.67 , $95 \% \mathrm{Cl} 0.68-4.05, \mathrm{p}=0.26)$.

CONCLUSIONS This study demonstrates no clear benefit to surgical decompression of penetrating $\mathrm{SCl}$ due predominantly to shrapnel. There is a considerable need for nonrandomized prospective cohort studies examining decompression and stabilization surgery for secondary and tertiary blast injuries.

https://thejns.org/doi/abs/10.3171/2017.5.SPINE161037

KEY WORDS secondary blast injury; penetrating spinal cord injury; surgical versus nonsurgical management; meta-analysis; trauma

$\mathrm{T}$ HE recent conflicts in Iraq and Afghanistan have seen the highest rates of spinal column injuries of any modern conflict. ${ }^{6,823}$ This includes penetrating spinal cord injuries (SCIs), more than one-third of which were caused by explosive mechanisms. ${ }^{2,6,8}$ There are numerous reviews and opinions concerning the treatment and outcomes of penetrating SCI due to gunshot wounds. ${ }^{10,11,20,34,36}$ However, there is a paucity of literature as regards the management and outcome of such injuries due to explosive mechanisms. ${ }^{20,23}$ There are several indi-

ABBREVIATIONS AIS = American Spinal Injury Association Impairment Scale; CSF = cerebrospinal fluid; SCl = spinal cord injury .

SUBMITTED August 31, 2016. ACCEPTED May 12, 2017.

INCLUDE WHEN CITING Published online October 20, 2017; DOI: 10.3171/2017.5.SPINE161037. 
Search Syntax for MEDLINE (PubMed)

("blast injuries"[Mesh Terms] OR "bombs"[MeSH Terms] OR "War-Related Injuries"[MeSH Terms] OR blast[tiab] OR explosion[tiab] OR explosions[tiab] OR "bombs"[ tiab] OR "bomb"[ tiab] OR explosive[tiab] OR explosives[tiab] OR exploding[tiab] OR ordinance[tiab] OR IED[tiab] OR "improvised explosive device"[tiab] OR shell[tiab] OR grenade[tiab] OR missile[tiab] OR penetrating[tiab] OR ballistic[tiab] OR shrapnel[tiab] OR splinter[tiab])

AND ("Spinal Injuries"[Mesh] OR "spinal cord"[MeSH Terms] OR "spinal canal"[MeSH Terms] OR "spine"[MeSH Terms] OR spine[tiab] OR spinal[tiab] OR back[tiab] OR "spinal cord"[ tiab])

AND ("Spinal Injuries/surgery"[MeSH Terms] OR "Spinal Injuries/therapy"[MeSH Terms] OR "spinal cord injuries/surgery"[MeSH Terms] OR "Spinal Cord Injuries/therapy"[MeSH Terms] OR "Foreign Bodies/surgery"[MeSH Terms] OR "treatment outcome"[MeSH Terms] OR "Wounds, Penetrating/surgery"[MeSH Terms] OR management[tiab] OR treatment[tiab] OR surgery[tiab] OR surgical[tiab] OR "non-surgical"[tiab] OR "nonsurgical"[tiab] OR decompression [tiab] OR removal[tiab] OR laminectomy[tiab] OR therapy[tiab] OR therapies[tiab] OR conservative[tiab])

FIG. 1. Search syntax for MEDLINE (PubMed).

cations for the surgical management of penetrating SCI: rapid neurological deterioration, radiographic evidence of spinal cord or nerve root compression, mechanical instability, cerebrospinal fluid (CSF) leakage, abscess, and chronic pain.,14,22,25 However, the question of whether decompressive laminectomy can improve the chances of recovering neurological function in incomplete SCI due to shrapnel has not been adequately investigated..$^{16,25}$ Further, there have been no attempts to combine published data in a meta-analysis to better answer this question. Therefore, our objective in this study was to determine whether neurosurgical intervention improves neurological outcome better than conservative management in penetrating SCI due to shrapnel.

\section{Methods}

This study was performed following the Preferred Reporting Items for Systematic Reviews and Meta-Analyses (PRISMA) guidelines. ${ }^{28}$ Our research question was, "Does surgical management of penetrating SCI due to shrapnel improve neurological outcome?" The study inclusion criteria consisted of the following: 1) shrapnel or related term(s) as a source of penetrating SCI, 2) surgical and/or conservative management, and 3) randomized controlled trial, cohort study, case control study, or case series. Study exclusion criteria consisted of the following: 1) no admission or follow-up neurological status, and 2) case series with fewer than 5 subjects.

\section{Search Strategy}

On May 2, 2016, a literature search of indexed peerreviewed articles was performed using the National Center for Biotechnology Information database (PubMed/ MEDLINE), Web of Science, Google Scholar, and the Defense Technical Information Center (DTIC) public site. The search strategy syntax for PubMed/MEDLINE is illustrated in Fig. 1. The same search terms were used with the other databases. The search was restricted to Englishlanguage articles published after 1985. Titles and abstracts discovered were reviewed to determine if the study met the inclusion criteria. The full text of those articles meeting the inclusion criteria were then reviewed to determine if the exclusion criteria applied, and a hand search of the references was performed to identify further relevant articles. Duplicate studies were excluded.

\section{Data Collection}

Studies meeting the eligibility criteria were independently reviewed (M.H.L. and E.J.L.). Data points extracted from each article included the following: authors, year of publication, number of patients, level of evidence, mechanism of injury, level of injury, degree of neurological injury (complete SCI, incomplete SCI), management (neurosurgical [that is, laminectomy, corpectomy with stabilization, and so forth] or conservative [that is, washout, soft-tissue debridement, bracing, and so forth]), neurological outcomes, mean follow-up time, complications, and age range (http://www.cebm.net/ocebm-levelsof-evidence/). Level of injury, mechanism of injury, and age were included for patients who did not have recorded neurological outcome in order to better characterize the overall pattern of injury. The proportion of study patients receiving surgical or conservative management was extracted to determine treatment bias. Admission neurological status of the patients was extracted to address potential selection bias by the study authors. The quality of case series was assessed using a 9-point checklist published by the National Heart, Lung, and Blood Institute of the National Institutes of Health (https://www.nhlbi.nih.gov/ health-pro/guidelines/in-develop/cardiovascular-riskreduction/tools/case-control). For studies that delineated individual neurological outcomes based on etiology and level of injury, subjects who were not injured by shrapnel and/or experienced lumbosacral injuries were excluded. ${ }^{4}$

Several data items were simplified to include the most articles for analysis. The first simplification was the dichotomization of admission neurological status into "complete" or "incomplete" SCI for those who had received surgical or conservative management. Secondly, follow-up neurological status was dichotomized into "not improved" or "improved."

Complete SCI was defined as a Frankel or American Spinal Injury Association (ASIA) Impairment Scale (AIS) Grade A, total motor and sensory loss below the level of injury, or paraplegia with bladder and bowel dysfunction or tetraplegia. Incomplete SCI was defined as a Frankel or 


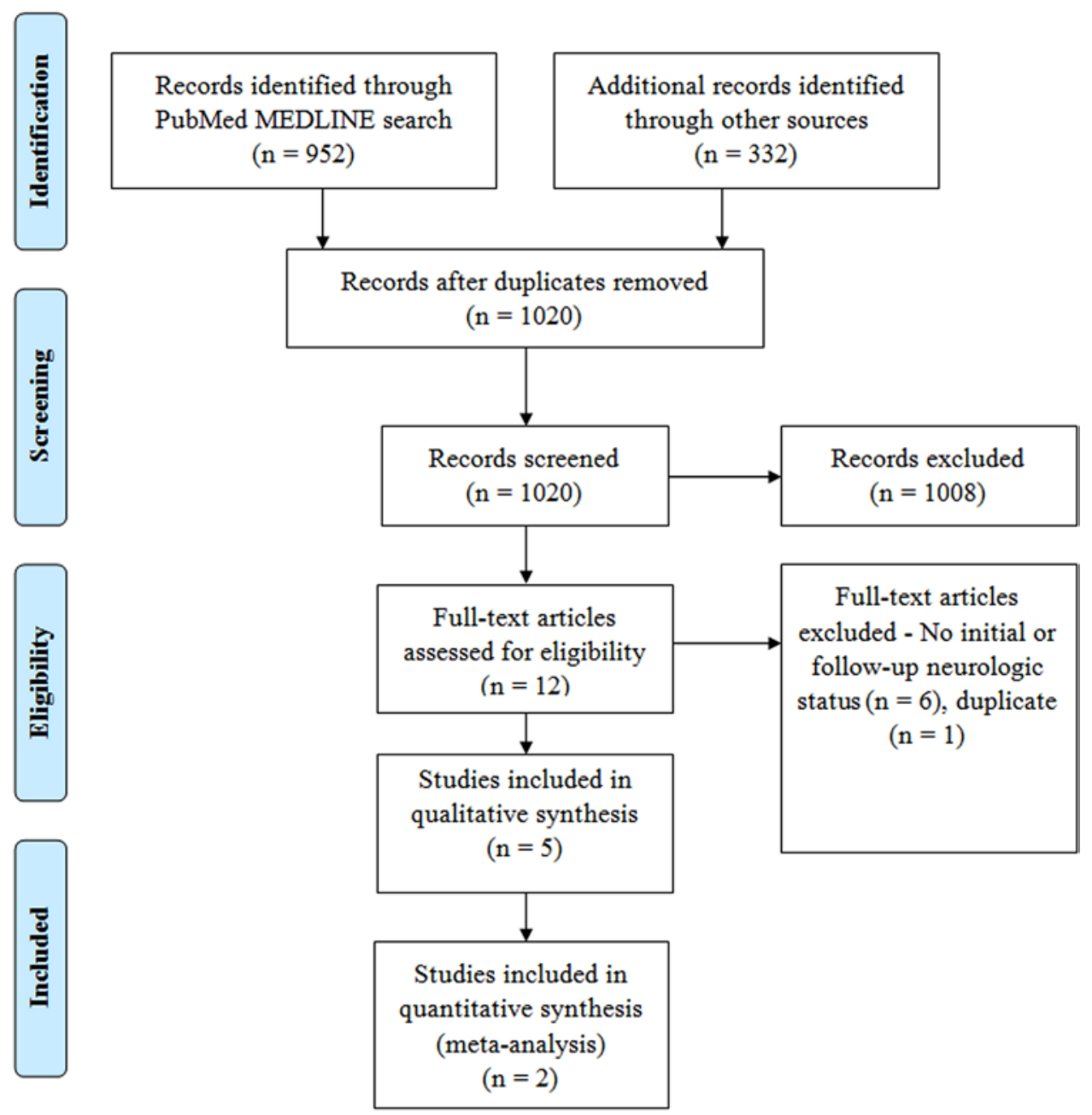

FIG. 2. Flow diagram for study selection. Data added to the PRISMA template (from Moher D, Liberati A, Tetzlaff J, Altman DG, The PRISMA Group [2009]: Preferred Reporting Items for Systematic Reviews and Meta-Analyses: The PRISMA Statement. BMJ 339:b2535, 2009) under the terms of the Creative Commons Attribution License. Figure is available in color online only.

AIS Grade B-D or milder neurological deficits, defined in one particular article as paraparesis, monoplegia, or paresthesia. ${ }^{38}$ "No change or worsened" neurological outcome was defined as the same or a lower Frankel or AIS grade at admission and follow-up. "Improved" neurological outcome was defined as improvement in the Frankel or AIS grade from admission to follow-up or mild or full recovery, as described in one article. ${ }^{38}$

Patients with an initial Frankel or AIS Grade E were excluded from data collection as this classification represents no neurological deficit. ${ }^{14,24}$ Patients included in the initial neurological evaluation but lost to follow-up were excluded from data collection. Patients who died were also excluded from data analysis as they most often died of multiple extensive organ system injuries. ${ }^{4,14,38}$

\section{Meta-Analysis}

Statistical analysis was performed using review manager software RevMan 5.3 (Cochrane Collaboration). For each study, the number of patients receiving neurosurgical or conservative management was identified and stratified by complete or incomplete SCI on admission and then dichotomized into "not improved" at follow-up or "improved" at follow-up. The Mantel-Haenszel method using the random effects model was performed to calculate each study's and the overall odds ratios. Heterogeneity was measured using the $\mathrm{I}^{2}$ statistic. ${ }^{12}$ Publication bias was graphically assessed using a funnel plot to evaluate for overestimation of effect across the studies. ${ }^{15,18}$ Descriptive statistics were performed using Microsoft Excel 2007 software. Significance was defined as $\mathrm{p}<0.05$.

\section{Results}

\section{Study Selection}

Our search strategy identified 1284 articles (Fig. 2). After excluding duplicates and studies that did not meet inclusion criteria, 12 remained. Of those, 6 more were excluded given the absence of a neurological exam at admission or follow-up. . $16,21,22,35,41$ One study was excluded because of a duplicate patient group. ${ }^{37}$

\section{Study Data}

Data summaries for the 5 studies included in a litera- 


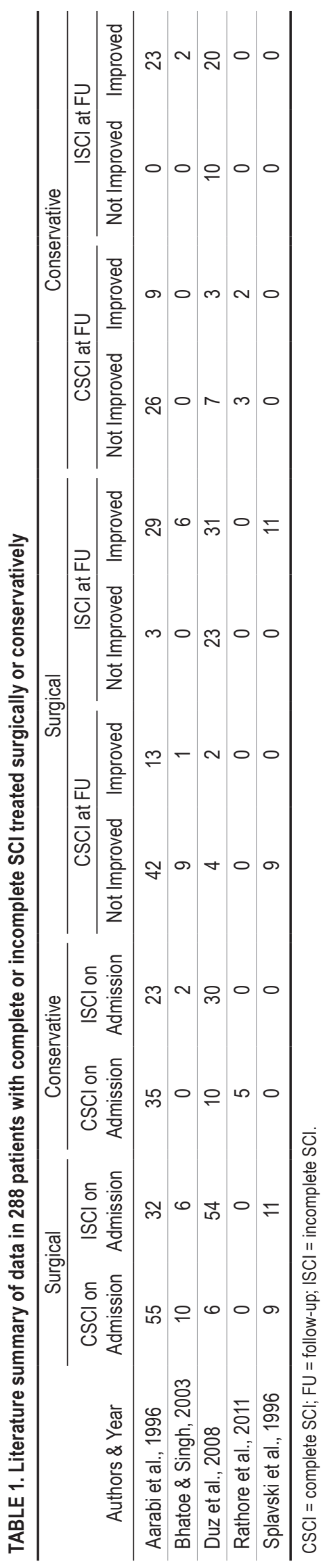

ture review are listed in Tables 1-3. The mechanism of injury was extracted from admission data reported on 383 patients, of whom 249 (65\%) were injured by shrapnel, $97(25 \%)$ by high-velocity bullet, $30(8 \%)$ by low-velocity bullet, and 7 (2\%) by an undetermined cause. ${ }^{1,4,14,33,38}$ Injuries occurred in the cervical region in 89 patients $(23 \%)$, thoracic region in $158(41 \%)$, lumbosacral region in 134 $(35 \%)$, and were not reported in $2(0.5 \%)$. The mean age ranged from 20 to 31 years. Among the studies reporting follow-up time, the range was 6-12 months. A total of 183 patients received neurosurgical treatment and 105 had conservative management. The mean time from injury to neurosurgical evaluation ranged from 0.83 to 84 hours. The mean time from injury to surgery ranged from 2.4 to 151.2 hours.

\section{Complete SCl}

Based on the severity of neurological injury on admission, patients were stratified into complete (130 patients) or incomplete (158 patients) SCI (Table 1). Of the patients who presented with complete SCI, 80 were managed with neurosurgical intervention. Among this cohort, 16 had an improved neurological status at follow-up. The other 50 patients with complete SCI were managed conservatively. Among this cohort, 14 had an improved neurological status at follow-up. A comparison of surgical and nonsurgical treatment in patients with complete SCI produced an overall OR of $1.56,95 \%$ CI $0.68-3.55$, and z-statistic of $1.05(\mathrm{p}=0.29)$, revealing no significant difference in outcomes.

\section{Incomplete SCI}

Of the patients who presented with incomplete SCI at admission, 103 were managed with neurosurgical intervention. Of these, $77 \mathrm{had}$ an improved neurological status at follow-up. The other 55 patients with incomplete SCI were managed conservatively. Among this cohort, 45 had an improved neurological status at follow-up. A comparison of surgical and nonsurgical treatment in patients with incomplete SCI produced an overall OR of $1.52,95 \%$ CI $0.67-3.44$, and $\mathrm{z}$-statistic of $1.00(\mathrm{p}=0.32)$, again showing no significant difference in outcomes.

\section{Meta-Analysis}

Of the 5 studies included in our literature review, only 2 provided adequate data for incorporation into the metaanalysis. ${ }^{1,14}$ A total of 245 patients were included in the overall odds ratio calculations for incomplete and complete SCI. In the complete SCI group that received surgical treatment, the overall odds of no change or worsened neurological status at follow-up was determined to be 1.07 (95\% CI 0.44-2.61, $\mathrm{p}=0.88$; Fig. 3). The overall rate of improvement in the complete SCI cohort was $25 \%$ with surgery and $27 \%$ with conservative treatment. For the incomplete SCI cohort that received surgical treatment, the overall odds of no change or worsened neurological status at follow-up was 1.67 (95\% CI 0.68-4.05, $\mathrm{p}=0.26$; Fig. 4). The overall rate of improvement in the incomplete SCI cohort was $70 \%$ with surgery and $81 \%$ with conservative treatment. 
TABLE 2. Literature summary of data in 388 patients with complete and incomplete SCI

\begin{tabular}{|c|c|c|c|c|c|c|c|}
\hline \multirow[b]{2}{*}{ Authors \& Year } & \multicolumn{3}{|c|}{ Level of Injury } & \multicolumn{3}{|c|}{ Mechanism of Injury (\% of total patients admitted) } & \multirow{2}{*}{$\begin{array}{l}\text { Mean Age, } \\
\text { Range (yrs) }\end{array}$} \\
\hline & Cervical & Thoracic & Lumbosacral & Shrapnel & High-Velocity Bullet & Low-Velocity Bullet & \\
\hline Aarabi et al., 1996 & $19 \%$ & $50 \%$ & $31 \%$ & $67 \%$ & $29 \%$ & NR & NR \\
\hline Bhatoe \& Singh, 2003 & $29 \%$ & $57 \%$ & $14 \%{ }^{*}$ & $77 \%$ & $0 \%$ & $23 \% *$ & 31 \\
\hline Duz et al., 2008 & $30 \%$ & $24 \%$ & $46 \%$ & $59 \%$ & $29 \%$ & $12 \%$ & $20,17-23$ \\
\hline Rathore et al., 2011 & $0 \%$ & $100 \%$ & $0 \%$ & $100 \%$ & $0 \%$ & $0 \%$ & $30,20-52$ \\
\hline Splavski et al., 1996 & $19 \%$ & $38 \%$ & $43 \%$ & $57 \%$ & $0 \%$ & $43 \%$ & $31,12-53$ \\
\hline
\end{tabular}

NR = not reported.

* Group excluded from Forest plot analysis as individual neurological outcome was defined based on mechanism of injury and could be

removed to limit confounding injury pattern.

\section{Complications}

Three studies detailed complications during treatment of SCI, which are listed in Table 3. One study demonstrated a higher incidence of complications in the surgical group than the conservative treatment group. ${ }^{1}$ However, another study showed similar rates between the 2 treatment groups, and the other included only patients treated surgically with no comparison. ${ }^{14,38}$

\section{Publication Bias}

The funnel plots for overall neurological improve- ment for complete SCI and incomplete SCI were analyzed (Figs. 5 and 6). However, given the small number of studies, the power of the funnel plot may be too low to determine real asymmetry.

\section{Discussion}

Recent military engagements and acts of terrorism have seen a rise in the use of explosive devices in areas such as Syria, Iraq, Afghanistan, and Yemen. 6,7,23,33 In Operation Iraqi Freedom and Operation Enduring Freedom, explosive devices used by enemy combatants produced

TABLE 3. Literature summary of complications in complete or incomplete SCI patients following surgical or conservative treatment

\begin{tabular}{|c|c|c|c|c|c|c|}
\hline $\begin{array}{c}\text { Authors } \\
\text { \& } \\
\text { Year }\end{array}$ & $\begin{array}{l}\text { No. of Deaths } \\
\text { (excluded from } \\
\text { analysis) }\end{array}$ & Surgical Intervention & Complications & $\begin{array}{c}\text { Mean Time From } \\
\text { Injury to Neurosurgical } \\
\text { Evaluation, Range } \\
\text { (hrs) }\end{array}$ & $\begin{array}{l}\text { Mean Time From } \\
\text { Injury to Surgical } \\
\text { Intervention, } \\
\text { Range (days) }\end{array}$ & $\begin{array}{l}\text { Mean Time From } \\
\text { Intervention to } \\
\text { FU Evaluation, } \\
\text { Range (mos) }\end{array}$ \\
\hline $\begin{array}{l}\text { Aarabi et } \\
\quad \text { al., } 1996\end{array}$ & 0 & $\begin{array}{l}\text { Decompression w/ } \\
\text { removal of intraca- } \\
\text { nal fragments, 55; } \\
\text { NR, } 32\end{array}$ & $\begin{array}{l}\text { Surgical: } \\
\text { CSF fistula, 13; } \\
\text { meningitis, 13 } \\
\text { Conservative: } \\
\text { CSF fistula, 4; } \\
\text { meningitis, } 2\end{array}$ & $84,24-792$ & $6.3,1-49$ & 6 \\
\hline $\begin{array}{c}\text { Bhatoe \& } \\
\text { Singh, } \\
2003\end{array}$ & $\begin{array}{l}1 \text {, surgical, } \mathrm{CSCl} \\
3 \text {, conservative, } \mathrm{CSCl}\end{array}$ & $\begin{array}{l}\text { Ant cervical corpec- } \\
\text { tomy \& fusion, 2; } \\
\text { laminectomy, 10; } \\
\text { lat decompression, } \\
\text { 1; debridement, } 5\end{array}$ & None reported & NR & NR & NR \\
\hline $\begin{array}{l}\text { Duz et al., } \\
2008\end{array}$ & $\begin{array}{l}\text { 4, surgical, CSCl } \\
\text { 4, surgical, ISCl } \\
\text { 4, conservative, CSCl } \\
\text { 4, conservative, ISCl }\end{array}$ & $\begin{array}{l}\text { Stabilization proce- } \\
\text { dure, 24; cervical } \\
\text { rhizotomy, 3; NR, } \\
33\end{array}$ & $\begin{array}{l}\text { Surgical: } \\
\text { CSF leak, 8; men- } \\
\text { ingitis, 3; chronic } \\
\text { pain, } 2 \\
\text { Conservative: } \\
\text { CSF leak, 2; men- } \\
\text { ingitis, } 7 \text {; chronic } \\
\text { pain, } 1\end{array}$ & $28,10-46$ & $4,0.8-7.2$ & 12 \\
\hline $\begin{array}{r}\text { Rathore et } \\
\text { al., } 2011\end{array}$ & 0 & NR & None reported & NR & NR & $12,6-12$ \\
\hline $\begin{array}{r}\text { Splavski et } \\
\text { al., } 1996\end{array}$ & 1 , surgery, CSCl & $\begin{array}{l}\text { Laminectomy, 17; } \\
\text { internal fixation, 1; } \\
\quad \mathrm{NR}, 2\end{array}$ & $\begin{array}{l}\text { Surgical: } \\
\text { CSF leak, 2; men- } \\
\text { ingitis, } 1\end{array}$ & 0.8 & 0.1 & NR \\
\hline
\end{tabular}

Ant $=$ anterior. 


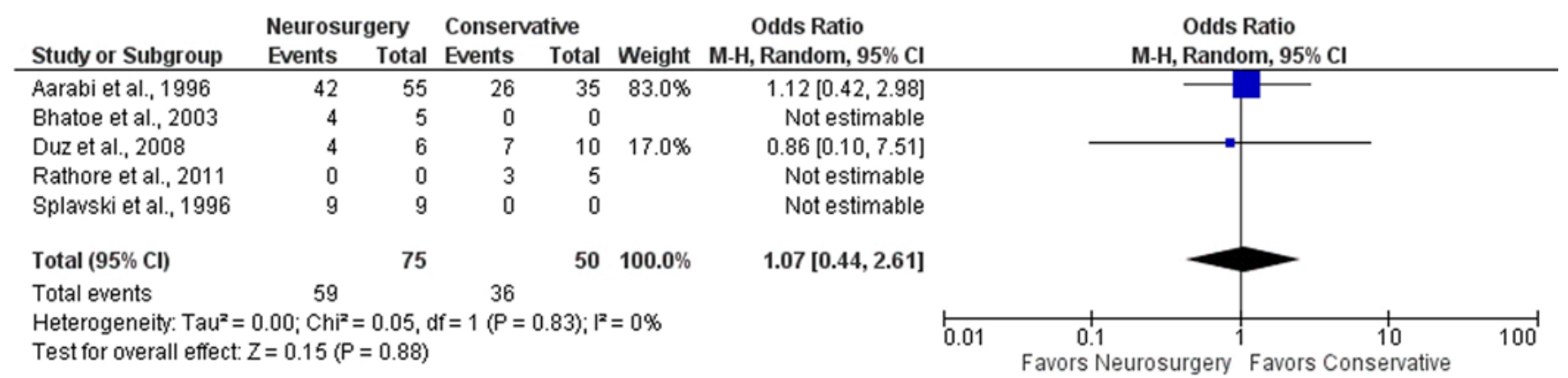

FIG. 3. Forest plot for complete SCI surgery versus conservative treatment. Events indicate no change or worse neurological grade at follow-up. $\mathrm{M}-\mathrm{H}=$ Mantel-Haenszel. Figure is available in color online only.

the largest burden of SCIs incurred by US troops in any modern conflict. ${ }^{7,31}$ Blair et al. found that explosives were responsible for more than half of all spinal injuries during these conflicts, with a third of those sustaining penetrating injury to the spine. ${ }^{7}$

Secondary blast injuries are defined as "ballistic injury from primary bomb casing fragments ... [or] from secondary fragments" (for example, ball bearings, metallic debris). ${ }^{23}$ The destructive capability of a missile is determined by the kinetic energy it delivers to tissue, commonly calculated as $\mathrm{KE}=1 / 2 \mathrm{mv}^{2}$. Hence, the major determinant of the energy transferred to neural tissue by a missile is the velocity at impact. ${ }^{16,25}$ Propelled shrapnel fragments can have initial velocities of up to $3000 \mathrm{~m} /$ sec; however, average impact velocities are cited at 300 $\mathrm{m} / \mathrm{sec}$ given the irregular shape and trajectory of these fragments. ${ }^{14,17,19,25,32}$ Military rifles such as the AK-47, on the other hand, have muzzle velocities of approximately $900 \mathrm{~m} / \mathrm{sec}^{9,}{ }^{9,26,29}$ Consequently, the kinetic energy delivered to tissue from shrapnel, compared with that from a highvelocity bullet, is considerably less in most instances. ${ }^{30,41}$ Evidence of this was shown by Blair et al., who found that complete SCI occurred 3.78 times more often in persons injured by a high-velocity bullet than from an explosive device. ${ }^{7}$ In addition to direct neural damage, injury can be incurred from the rapid accelerating and decelerating concussive forces from the blast wave of an explosion. ${ }^{23,39}$ This is referred to as "tertiary blast injury" and can cause blunt trauma to the spinal column leading to biomechanical instability as well. ${ }^{23}$ These concepts formed the rationale for this study, namely to determine whether a difference in neurological outcome might be seen when comparing the management of those injured by shrapnel versus those injured by high-velocity bullets.

Our meta-analysis of 245 patients pooled from 2 large case series did not indicate a statistically significant benefit for surgical decompression. ${ }^{1,14}$ Our findings are consistent with those from other reviews that examined bullets as the cause of penetrating SCI and for which decompression did not lead to better neurological outcomes. ${ }^{10,11,36}$ Most authors agree that decompression should be performed for indications such as progressive neurological deficit, persistent CSF leakage, infection, and spinal instability; however, these conclusions are based on expert opinion alone. ${ }^{9-11,25}$

No published studies have directly compared surgical decompression to conservative management for penetrating SCI solely due to penetrating blast injury. However, in the literature we found 2 large case series with a patient population predominantly injured by shrapnel (64\%) and a minority of patients who had sustained injuries from highvelocity gunshot wounds (29\%).,14 The 5 included studies did not define the outcomes of patients whose neurological compromise was attributable to bony compression due to fracture and/or dislocation (tertiary injury) as opposed to direct shrapnel penetration (secondary injury). In cases of tertiary injury, the SCI may owe more to contusion from dissipation of energy from the blast wave. ${ }^{27}$ This could explain greater recovery of neurological function. Accordingly, patients with tertiary injury may still do better with decompression and stabilization than those with incomplete SCI as a result of direct cord injury from the shrapnel.

Authors of a recent systematic review of civilian gun-

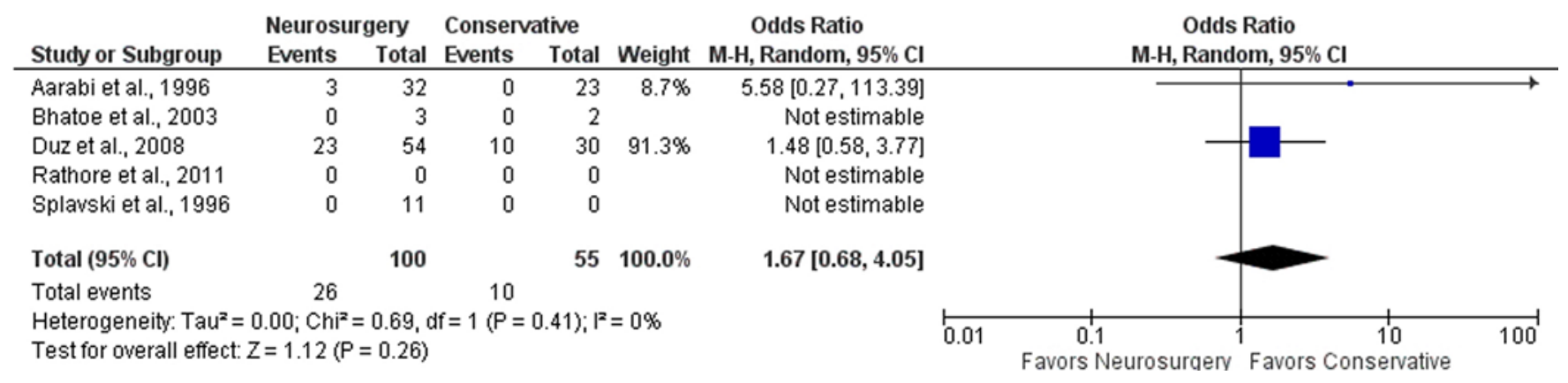

FIG. 4. Forest plot for incomplete SCI surgery versus conservative treatment. Events indicate no change or worse neurological grade at follow-up. Figure is available in color online only. 


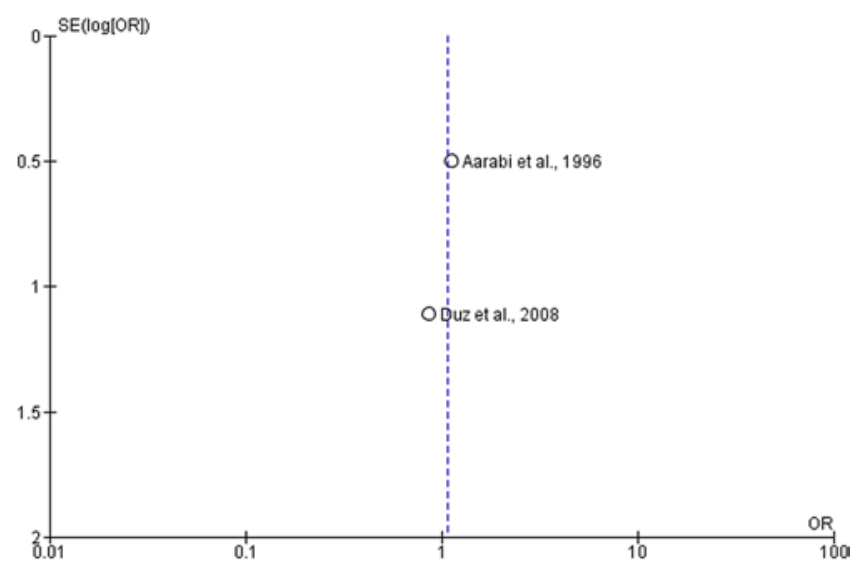

FIG. 5. Funnel plot of complete SCI studies. SE = standard error. Figure is available in color online only.

shot wounds causing penetrating SCI concluded that surgical decompression may be beneficial in patients with progressive incomplete lesions and radiographic evidence of compression. ${ }^{36}$ Our results did not show a similar trend for greater neurological benefit with surgical decompression. We found the odds of no improvement in neurological function following surgical management to be 1.67 $(95 \%$ CI $0.68-4.05, \mathrm{p}=0.26)$ for incomplete spinal cord lesions. However, a larger patient cohort with blast injury in a prospective nonrandomized study would provide the large sample size necessary to determine the efficacy of these interventions. This would be especially true in determining whether there is greater neurological recovery with decompression and stabilization in patients with secondary versus tertiary blast injury.

Another factor to consider in future studies is whether the time to surgery affects neurological recovery. Biglari et al. performed a prospective cohort study of nonpenetrating traumatic SCI, comparing patients who underwent surgery less than 4 hours after injury with those who did so 4-24 hours after injury. ${ }^{5}$ These authors, after controlling for possible cofounding variables, found no significant differences in neurological recovery following decompression and stabilization in the early versus late surgical cohorts. ${ }^{5}$ Wilson et al. performed a similar prospective cohort study; however, the mean time to surgical intervention was 12 and 155 hours after injury. ${ }^{40}$ After controlling for neurological level of injury and preoperative neurological status, these authors found that patients who had undergone surgical decompression less than 24 hours after injury had statistically significant greater neurological recovery than those with decompression more than 24 hours after injury. ${ }^{40}$ Optimal timing for surgical intervention may be within 24 hours of injury, although further investigation is needed.

As of now, however, our observations are not too dissimilar from Dr. Harvey Cushing's observations during World War I, when he noted that "only those cases survived in which the spinal lesion was a partial one."13

\section{Study Limitations}

Our study has several important limitations that must

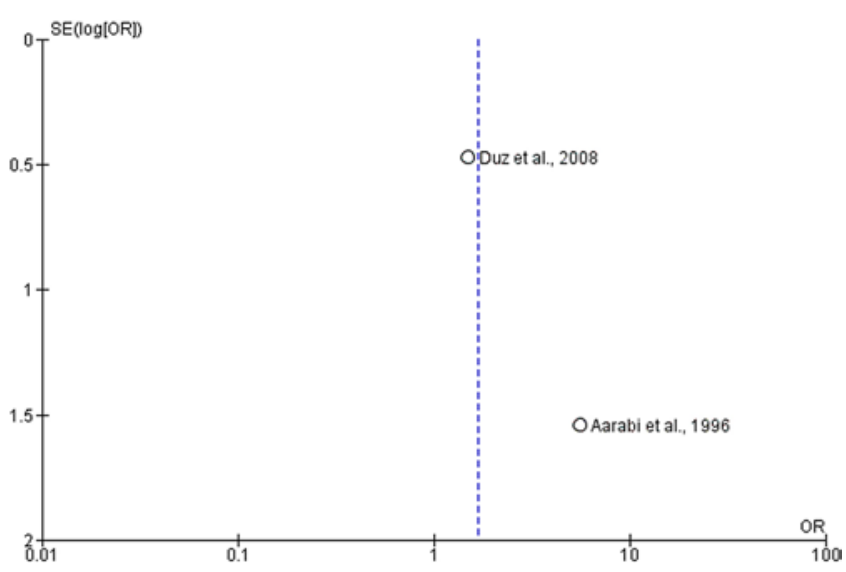

FIG. 6. Funnel plot of incomplete $\mathrm{SCl}$ studies. Figure is available in color online only.

be reflected on when reviewing our results. First, there is a dearth of high-level evidence-based studies performed on penetrating SCI due to shrapnel. This is understandable given the ethical concerns of not performing current expert-recommended decompression and the rarity of this type of injury. Thus, the only available published data consisted of small case series. These types of studies allow for selection bias for neurosurgical treatment versus nonsurgical management that could confound effectiveness.

Moreover, among the studies included in our literature review, there was considerable heterogeneity in terms of injuries, surgical interventions, and follow-up, which are all potential cofounders. In particular, the follow-up period could potentially be quite confounding for those managed conservatively, as an increased rehabilitative period could allow for greater neurological recovery. Further, cauda equina injuries could not be separated from spinal cord injuries due to a lack of individual patient data, potentially confounding our results. Another limitation is the minority of patients injured by high-velocity gunshot wounds in the 2 studies included in our meta-analysis, a factor that may have skewed the data.

\section{Conclusions}

Shrapnel injury represents a significant proportion of penetrating SCIs, and the incidence of SCI due to explosive shrapnel has increased in recent military conflicts. Also contributing to this increase are acts of terrorism, to a much higher degree than in any previous time period. Our analyses revealed no significant difference between surgical and nonsurgical management for complete and incomplete SCI due to penetrating injury predominantly from shrapnel. Our study indicates the need for further investigation into the most appropriate management for this patient population given that aggressive surgical management, as compared with conservative measures, did not lead to significantly improved neurological recovery.

\section{Acknowledgments}

We thank Ms. Tracy Shields for her assistance with the literature search and Ms. June Brockman for her editorial assistance. 


\section{References}

1. Aarabi B, Alibaii E, Taghipur M, Kamgarpur A: Comparative study of functional recovery for surgically explored and conservatively managed spinal cord missile injuries. Neurosurgery 39:1133-1140, 1996

2. Bernstock JD, Caples CM, Wagner SC, Kang DG, Lehman RA Jr: Characteristics of combat-related spine injuries: a review of recent literature. Mil Med 180:503-512, 2015

3. Bhat AR, Wani MA, Kirmani AR, Alam S, Raina T, Arif $\mathrm{S}$, et al: Missile injuries of spine and spinal cord in civilian Kashmir-analysis and outcome evaluated by new Modified SKIMS-Functional Scales. Indian J Neurotrama 9:99-111, 2012

4. Bhatoe HS, Singh P: Missile injuries of the spine. Neurol India 51:507-511, 2003

5. Biglari B, Child C, Yildirim TM, Swing T, Reitzel T, Moghaddam A: Does surgical treatment within 4 hours after trauma have an influence on neurological remission in patients with acute spinal cord injury? Ther Clin Risk Manag 12:1339-1346, 2016

6. Blair JA, Patzkowski JC, Schoenfeld AJ, Cross Rivera JD, Grenier ES, Lehman RA, et al: Are spine injuries sustained in battle truly different? Spine J 12:824-829, 2012

7. Blair JA, Patzkowski JC, Schoenfeld AJ, Cross Rivera JD, Grenier ES, Lehman RA, et al: Spinal column injuries among Americans in the global war on terrorism. J Bone Joint Surg Am 94:e135(1)-e135(9), 2012

8. Blair JA, Possley DR, Petfield JL, Schoenfeld AJ, Lehman RA, Hsu JR: Military penetrating spine injuries compared with blunt. Spine J 12:762-768, 2012

9. Bono CM, Heary RF: Gunshot wounds to the spine. Spine J 4:230-240, 2004

10. Bumpass DB, Buchowski JM, Park A, Gray BL, Agarwal R, Baty J, et al: An update on civilian spinal gunshot wounds: treatment, neurological recovery, and complications. Spine (Phila Pa 1976) 40:450-461, 2015

11. de Barros Filho TE, Cristante AF, Marcon RM, Ono A, Bilhar R: Gunshot injuries in the spine. Spinal Cord 52:504510, 2014

12. Deeks J, Higgins J, Altman D: Chapter 9: Analysing data and undertaking meta-analyses, in Higgins JPT, Green S (eds): Cochrane Handbook for Systematic Reviews of Interventions, Version 5.1.0. London: The Cochrane Collaboration, 2011 (http://handbook.cochrane.org) [Accessed June 22, 2017]

13. Donovan WH: Donald Munro Lecture. Spinal cord injurypast, present, and future. J Spinal Cord Med 30:85-100, 2007

14. Duz B, Cansever T, Secer HI, Kahraman S, Daneyemez MK, Gonul E: Evaluation of spinal missile injuries with respect to bullet trajectory, surgical indications and timing of surgical intervention: a new guideline. Spine (Phila Pa 1976) 33:E746-E753, 2008

15. Egger M, Davey Smith G, Schneider M, Minder C: Bias in meta-analysis detected by a simple, graphical test. BMJ 315:629-634, 1997

16. Hammoud MA, Haddad FS, Moufarrij NA: Spinal cord missile injuries during the Lebanese civil war. Surg Neurol 43:432-442, 1995

17. Hayda R, Harris RM, Bass CD: Blast injury research: modeling injury effects of landmines, bullets, and bombs. Clin Orthop Relat Res (422):97-108, 2004

18. Higgins JPT, Green S (eds): Cochrane Handbook for Systematic Reviews of Interventions, Version 5.1.0. London: The Cochrane Collaboration, 2011(http://handbook.cochrane. org) [Accessed June 22, 2017]

19. Hill PF, Edwards DP, Bowyer GW: Small fragment wounds: biophysics, pathophysiology and principles of management. J R Army Med Corps 147:41-51, 2001
20. Jakoi A, Iorio J, Howell R, Zampini JM: Gunshot injuries of the spine. Spine J 15:2077-2085, 2015

21. Janković S, Busić Z, Primorac D: Spine and spinal cord war injuries during the war in Croatia. Mil Med 163:847-849, 1998

22. Kahraman S, Gonul E, Kayali H, Sirin S, Duz B, Beduk A, et al: Retrospective analysis of spinal missile injuries. Neurosurg Rev 27:42-45, 2004

23. Kang DG, Lehman RA Jr, Carragee EJ: Wartime spine injuries: understanding the improvised explosive device and biophysics of blast trauma. Spine J 12:849-857, 2012

24. Kirshblum SC, Burns SP, Biering-Sorensen F, Donovan W, Graves DE, Jha A, et al: International standards for neurological classification of spinal cord injury (revised 2011). J Spinal Cord Med 34:535-546, 2011

25. Klimo P Jr, Ragel BT, Rosner M, Gluf W, McCafferty R: Can surgery improve neurological function in penetrating spinal injury? A review of the military and civilian literature and treatment recommendations for military neurosurgeons. Neurosurg Focus 28(5):E4, 2010

26. Knudsen PJ, Svender J: Doppler radar velocity measurements for wound ballistics experiments. Int J Legal Med 107:1-6, 1994

27. le Roux JC, Dunn RN: Gunshot injuries of the spine-a review of 49 cases managed at the Groote Schuur Acute Spinal Cord Injury Unit. S Afr J Surg 43:165-168, 2005

28. Moher D, Liberati A, Tetzlaff J, Altman DG: Preferred Reporting Items for Systematic Reviews and Meta-Analyses: The PRISMA Statement. BMJ 339:b2535, 2009

29. Patil R, Jaiswal G, Gupta TK: Gunshot wound causing complete spinal cord injury without mechanical violation of spinal axis: Case report with review of literature. J Craniovertebr Junction Spine 6:149-157, 2015

30. Peled M, Leiser Y, Emodi O, Krausz A: Treatment protocol for high velocity/high energy gunshot injuries to the face. Craniomaxillofac Trauma Reconstr 5:31-40, 2012

31. Possley DR, Blair JA, Freedman BA, Schoenfeld AJ, Lehman RA, Hsu JR: The effect of vehicle protection on spine injuries in military conflict. Spine J 12:843-848, 2012

32. Ramasamy A, Hill AM, Clasper JC: Improvised explosive devices: pathophysiology, injury profiles and current medical management. J R Army Med Corps 155:265-272, 2009

33. Rathore FA, Ayub A, Farooq S, New PW: Suicide bombing as an unusual cause of spinal cord injury: a case series from Pakistan. Spinal Cord 49:851-854, 2011

34. Rosenfeld JV, Bell RS, Armonda R: Current concepts in penetrating and blast injury to the central nervous system. World J Surg 39:1352-1362, 2015

35. Rukovansjki M: Spinal cord injuries caused by missile weapons in the Croatian war. J Trauma 40 (3 Suppl):S189-S192, 1996

36. Sidhu GS, Ghag A, Prokuski V, Vaccaro AR, Radcliff KE: Civilian gunshot injuries of the spinal cord: a systematic review of the current literature. Clin Orthop Relat Res 471:3945-3955, 2013

37. Splavski B, Vranković D, Blagus G, Mursić B, Iveković V: Spinal stability after war missile injuries of the spine. J Trauma 41:850-853, 1996

38. Splavski B, Vranković D, Sarić G, Blagus G, Mursić B, Rukovanjski M: Early management of war missile spine and spinal cord injuries: experience with 21 cases. Injury 27:699-702, 1996

39. Wolf SJ, Bebarta VS, Bonnett CJ, Pons PT, Cantrill SV: Blast injuries. Lancet 374:405-415, 2009

40. Wilson JR, Singh A, Craven C, Verrier MC, Drew B, Ahn $\mathrm{H}$, et al: Early versus late surgery for traumatic spinal cord injury: the results of a prospective Canadian cohort study. Spinal Cord 50:840-843, 2012

41. Zeilig G, Weingarden HP, Zwecker M, Rubin-Asher D, Rat- 
ner A, Ohry A: Civilian spinal cord injuries due to terror explosions. Spinal Cord 48:814-818, 2010

\section{Disclosures}

The opinions or assertions contained herein are the private views of the authors and are not to be construed as official or as reflecting the views of the United States Navy or Department of Defense. The authors report no conflict of interest concerning the materials or methods used in this study or the findings specified in this paper. Several of the authors are employees of the US government. This work was prepared as part of their official duties. Title 17 U.S.C. 105 provides that "Copyright protection under this title is not available for any work of the United States Government." Title 17 U.S.C. 101 defines a United States Government work as a work prepared by a military service member or employee of the United States government as part of that person's official duties.

\section{Author Contributions}

Conception and design: Lawless, Engler. Acquisition of data: Lawless, Lytle. Analysis and interpretation of data: Lawless, Lytle, McGlynn. Drafting the article: Lawless. Critically revising the article: Lawless, Lytle, Engler. Reviewed submitted version of manuscript: all authors. Approved the final version of the manuscript on behalf of all authors: Lawless. Statistical analysis: Lawless, McGlynn. Administrative/technical/material support: Lytle, McGlynn. Study supervision: Engler.

\section{Correspondence}

Michael H. Lawless, Providence-Providence Park Hospital, Michigan State University College of Human Medicine, 16001 West Nine Mile Rd., Southfield, MI 48075. email: michael.lawless3@ ascension.org. 